Z Gerontol Geriat 2022 · 55:129-134 https://doi.org/10.1007/s00391-022-02036-4 Received: 16 December 2021 Accepted: 31 January 2022

Published online: 4 March 2022

( $\odot$ The Author(s), under exclusive licence to Springer Medizin Verlag $\mathrm{GmbH}$, ein Teil von Springer Nature 2022, corrected publication 2022

\section{Terminal care in oldest old dying from COVID-19 in the acute hospital}

\section{A multicenter study describing pharmacological treatment in the last $24 \mathrm{~h}$}

Wim H. Janssens · Nele J. Van Den Noortgate $\cdot$ Ruth D. Piers

Department of Geriatrics, University Hospital Ghent, Ghent, Belgium

\title{
Abstract
}

Background: Coronavirus disease 2019 (COVID-19) has a high mortality, especially in the oldest old. Dying from COVID-19 is often characterized by symptoms such as breathlessness and agitation but data concerning medical treatment in the dying phase are limited.

Objective: This study describes the administration of oxygen, opioids and benzodiazepines in the last $24 \mathrm{~h}$ before death in patients 80 years or older dying from COVID-19 on acute hospital wards.

Material and methods: In this multi-centric retrospective study, patients, 80 years and older, admitted to the acute hospital in March and April 2020 were recruited from 10 acute Belgian hospitals. They all were diagnosed with COVID-19 and died on non-ICU wards with COVID-19. Administration of oxygen, opioids and benzodiazepines in the last $24 \mathrm{~h}$ before death was registered.

Results: Eighty-five percent of patients received oxygen, half of them even by means of a mask providing at least 10 l oxygen per minute. The majority $(84.3 \%)$ of patients were treated with opioids (morphine). Mean dosage of SC morphine equivalent was $31.3 \mathrm{mg} / 24 \mathrm{~h}$ (range $2-120 \mathrm{mg} ;$ SD $21.6 \mathrm{mg}$ ). More than half of patients (52.8\%) received benzodiazepines, mostly midazolam. Mean dosage of midazolam was $20.4 \mathrm{mg} / 24 \mathrm{~h}$ (range 1-100 mg; SD $15.4 \mathrm{mg}$ ). Dosages of morphine and midazolam did not differ depending on frailty or comorbidities. Older COVID-19 patients dying with respiratory failure had higher midazolam dosage ( $p 0.002)$ but not morphine dosage ( $p 0.11)$. Conclusion: A high proportion of patients 80 years and older and dying with COVID-19 in the hospital, were treated with oxygen, opioids and benzodiazepines in the last $24 \mathrm{~h}$ before death. With this descriptive study, we hope to contribute to the discussion and further research on the optimization of symptom control in an older population dying from/with COVID-19.

\section{Keywords}

SARS-CoV-2 $\cdot$ Aged, 80 years and over $\cdot$ End of life $\cdot$ Pharmacological treatment $\cdot$ Opioid

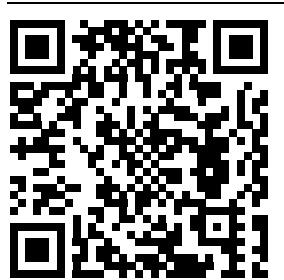

Scan QR code \& read article online

\section{Introduction}

A novel type of coronavirus, severe acute respiratory syndrome coronavirus 2 (SARSCoV-2), causing a severe acute respiratory infection known as coronavirus disease 2019 (COVID-19) emerged and has spread globally since December 2019.
The overall mortality of COVID-19 is estimated to be $1-3 \%$, [16] where patients with multimorbidity and older patients seem to have a higher risk of developing severe COVID-19 and a higher mortality $[8,15]$. In Belgium, from 1 March 2020 until 28 February $2021,82 \%$ of fatalities were older than 75 years and $53 \%$ older than 85 years [2]. 


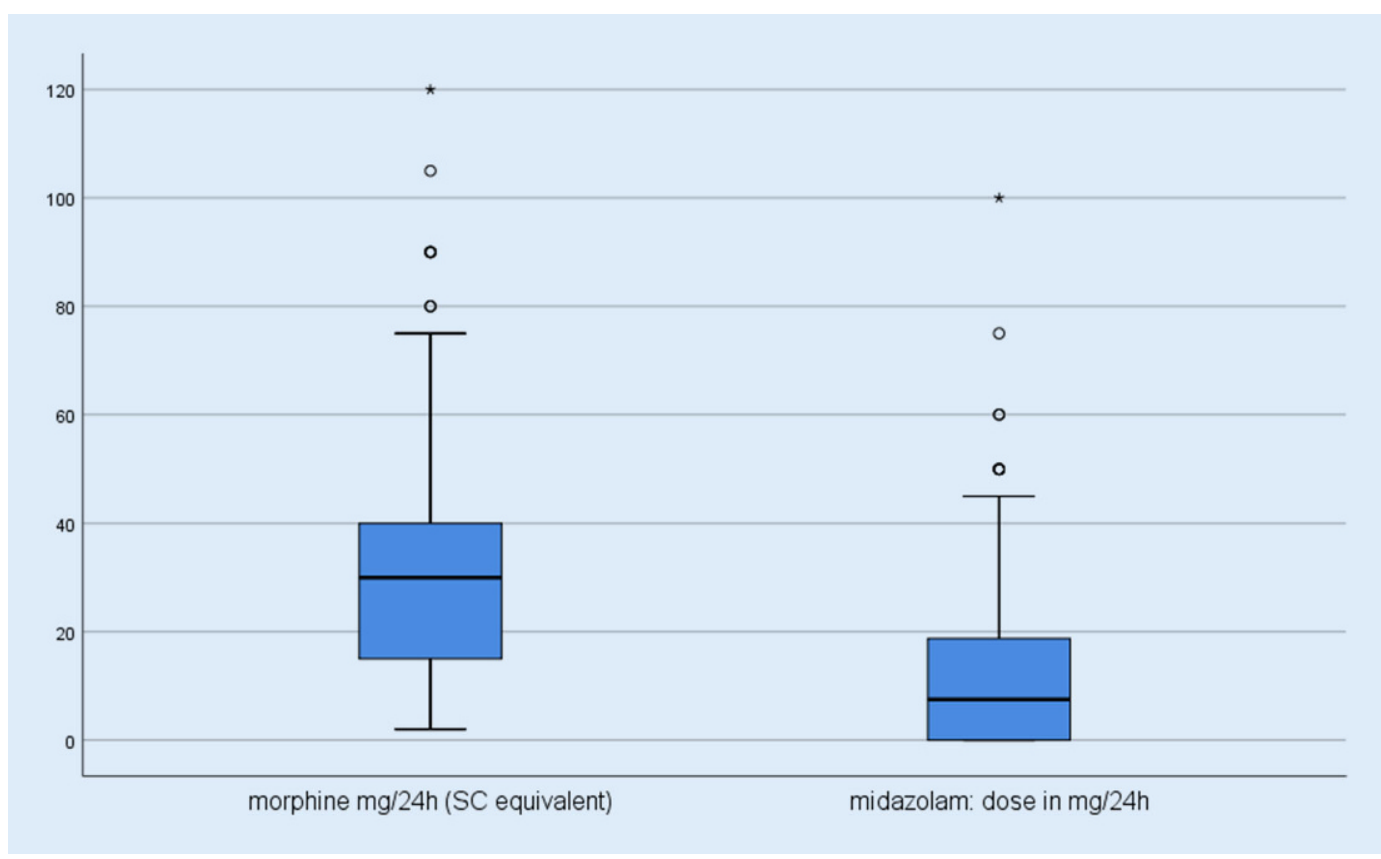

Fig. $1<$ Dosage of opioids (SC morphine equivalent) and benzodiazepines (reduced to midazolam) in patients treated with opioids and/or midazolam. SC subcutanuous, circle outside the $95 \%$ confidence interval, asterisk highest dosages
Dying from COVID-19 is often characterized by symptoms such as breathlessness and agitation [7]. A British study on a COVID-19 cohort on a palliative care unit showed, compared to a typical non-COVID cohort, a high prevalence of dyspnea and agitation, a higher death rate, a shorter stay and a high prescription rate of opioids and midazolam [4]. In a National Register Study in Sweden the authors advised to disseminate palliative guidelines to acute hospitals treating patients with COVID-19 [12]; however, data concerning medical treatment in the dying phase on acute hospital wards are scarce.

In this multi-centric retrospective study, we describe the administration of oxygen, opioids and benzodiazepines in the last $24 \mathrm{~h}$ before death in patients 80 years or older dying from COVID-19 on non-ICU wards in acute hospitals.

\section{Material and methods}

Patients admitted to the acute hospital in March and April 2020 were recruited from 10 acute Belgian hospitals.

Inclusion criteria were being 80 years or older, being diagnosed with COVID-19 based on SARS-CoV-2 PCR positivity and/or based on characteristic abnormalities on chest computed tomography, biochemistry and suggestive signs and symptoms and/or consensus on COVID-19 diagno- sis within multidisciplinary team meeting and dying with COVID-19. Patients dying on the intensive care unit (ICU) or being ventilated (mechanically or non-invasive) were excluded.

The study was approved by the central ethics committee (Ghent University Hospital, Belgian Registration number BC07858) and all local ethics committees. Informed consent was waived because of the retrospective and non-interventional nature of the study and because strict anonymity during data processing was guaranteed.

Sociodemographic data were registered. All of the following data that were collected, concerned the given treatment during the last $24 \mathrm{~h}$ before death: probable cause of death, administration of oxygen, opioids, including mean dosage and route of administration, doses reduced to subcutaneous (SC) morphine equivalent and benzodiazepines (including mean dosage and route of administration; doses reduced to a corresponding dose of midazolam, using a conversion table). In all patients, a premorbid clinical frailty score (CFS), a scale ranging from 1 (very fit) to 9 (terminally ill), and comorbidities were determined. Data on resuscitation orders were collected. In this study we dichotomized the resuscitation orders to consider intensive care versus do not escalate care (ward-based medical treatment but no admission to ICU). In Belgium, resuscitation orders must be discussed with the patients and/or their representative in cases of incapacity. Finally, the presence of respiratory failure was assessed and defined as follows: $\mathrm{PaO}_{2} \leq 60 \mathrm{mmHg}$ and/or low $\mathrm{SpO} 2 \quad(\leq 90 \%$ with supplemental oxygen or $\leq 88 \%$ without supplemental oxygen) and/or in need of more than $5 \mathrm{~L} / \mathrm{min}$ oxygen supplementation at any moment during hospital stay.

\section{Results}

A total of 711 patients 80 years or older with COVID-19 were hospitalized, 216 patients died and were included in the study. Of the patients 74 (34.3\%) were 80-84 years old, $88(40.7 \%)$ were $85-89$ years old and 54 (25\%) 90 years or older. There were slightly more women than men included (111 vs. 105). Before admission to the hospital, most of the patients lived at home (126; $58.3 \%)$ or in residential care $(81 ; 37.5 \%)$, 9 (4.2\%) patients resided in an assistedliving facility. Median premorbid CFS was 7 (severely frail). Comorbidities were frequent: more than $80 \%$ of patients suffered from cardiovascular disease, while dementia, metabolic and/or chronic kidney disease were present in about $40 \%$ of patients and $47 \%$ of all patients went into respiratory failure. This percentage was higher (73\%) in the patients dying from/ 


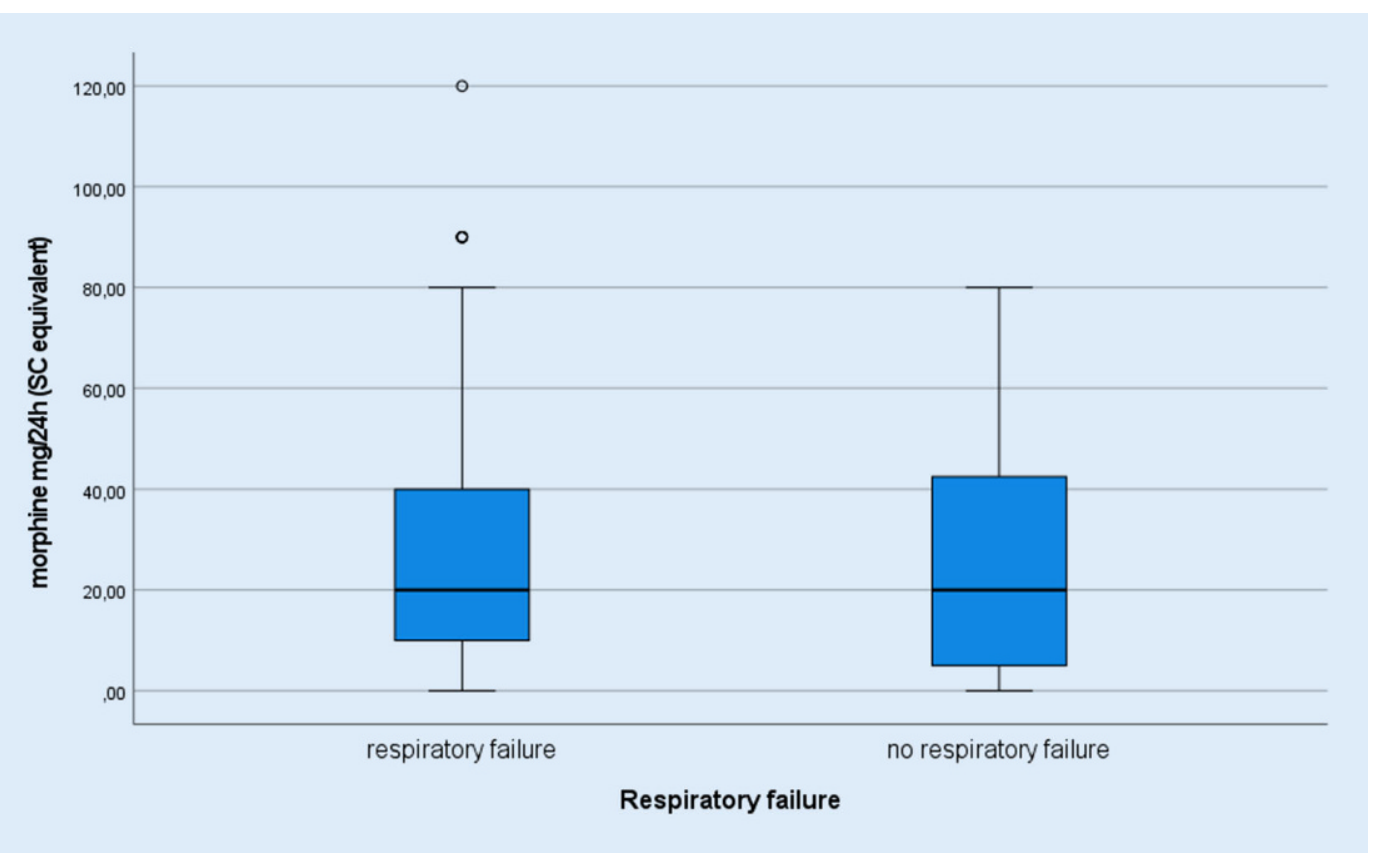

Fig. 24 Dosage of opioids (SC morphine equivalent) in patients with or without respiratory failure. Circle outside the $95 \%$ confidence interval with COVID-19, compared to the patients surviving COVID-19.

In 143 patients (66.2\%), death was caused by severe COVID-19, in 52 patients (24.1\%) death was due to progression of an underlying comorbidity and/or frailty aggravated by COVID-19, and in 19 patients (8.8\% of cases) COVID-19 was a comorbidity without probable attribution to death. In 2 patients cause of death was unclear. In 32 patients (14.8\%) no supplemental oxygen was given in the final $24 \mathrm{~h}$ of life. Respectively 60 (27.8\%), 23 (10.6\%) and $101(46.8 \%)$ patients received less than $5 \mathrm{I}, 6-9 \mathrm{l}$ or at least $10 \mathrm{l}$ oxygen per minute.

The majority $(182 ; 84.3 \%)$ of patients received opioids (morphine) in the last $24 \mathrm{~h}$. In $89 \%$ of them, morphine was administered subcutaneously, in $11 \%$ intravenously. Mean dosage of SC morphine equivalent was $31.3 \mathrm{mg} / 24 \mathrm{~h}$ (SD 21.6). The majority of patients receiving opioids (170; 93.5\%) were opioid naive.

More than half of patients $(114 ; 52.8 \%)$ received benzodiazepines during the $24 \mathrm{~h}$ before death. Most of them (89.6\%) were treated with midazolam. Midazolam was mostly administered subcutaneously (83.3\%). Mean dosage of midazolam was $20.4 \mathrm{mg} / 24 \mathrm{~h}$ (SD 15.4) (• Fig. 1).

There was no significant difference between patients who were very fit to moderately frail (CFS 1-6) and patients who were severely frail to terminally ill (CFS
7-9) concerning mean dosage of morphine ( $p$ 0.58) and midazolam ( $p$ 0.24). Neither was there a statistical significance in morphine ( $p 0.25)$ and midazolam ( $p 0.1)$ dosages when comparing patients with or without comorbidities (cardiovascular, renal, metabolic or dementia). There was no difference in dosage of morphine between patients with or without respiratory failure ( 0.11 ) (• Fig. 2), while patients with respiratory failure received a significantly higher dosage of midazolam ( $p$ 0.002) (- Fig. 3). The highest dosages of morphine and midazolam, however, were found in patients with respiratory failure (- Figs. 2 and 3 ).

\section{Discussion}

In contrast to other studies on patients with COVID-19 in nursing homes or in palliative care units, our study describes the use of opioids and midazolam in patients dying with COVID-19 on acute wards, being treated by certified geriatricians. We found that of 216 oldest old patients dying in 10 acute non-ICU wards in Belgian hospitals, $84.3 \%$ received opioids (mean dosage of SC morphine equivalent $31.3 \mathrm{mg} / 24 \mathrm{~h}$ ) and $52.8 \%$ received benzodiazepines (mean dosage of midazolam $20.4 \mathrm{mg} / 24 \mathrm{~h}$ ). Dosage of midazolam was, in contrast to dosage of morphine, associated with respiratory failure. Comparable data are scarce, es- pecially in the oldest old dying outside the specialized palliative care setting.

Lovell et al. found $57 \%$ of 101 in-hospital patients with COVID-19 referred to the hospital palliative care teams (mean age 82 years), being treated with morphine and/or midazolam (mean dose of morphine $10 \mathrm{mg} / 24 \mathrm{~h}$, mean dose of midazolam $10 \mathrm{mg} / 24 \mathrm{~h}$ ) [7]. In 2 studies in palliative care settings, 1 on 186 COVID19 patients (mean age 76 years) and 1 on 48 COVID-19 patients (mean age 75 years), respectively, $65 \%$ and $100 \%$ of patients received opioids, with a mean dose of $15 \mathrm{mg}$ morphine/ $24 \mathrm{~h}$, respectively, $14 \mathrm{mg}$ morphine $/ 24 \mathrm{~h}$, and midazolam, with a mean dose of $10 \mathrm{mg} / 24 \mathrm{~h}$ and $9.5 \mathrm{mg} / 24 \mathrm{~h}[4,5]$. Frequency of administration and dosage of morphine and midazolam in these studies were lower compared to our findings.

Apart from setting (specialized palliative care versus acute ward), differences in patient characteristics, such as age, place of death, cause of death (COVID-19 versus non-COVID-19) or symptomatology (allcause mortality versus dying from respiratory disease) may explain differences in use of opioids and hypnotics in dying patients.

In non-COVID-19 situations, frequency of administration of strong opioids at the end of life seems to be lower. In a study by Sandvik et al. in dying nursing home patients, the administration of strong and 


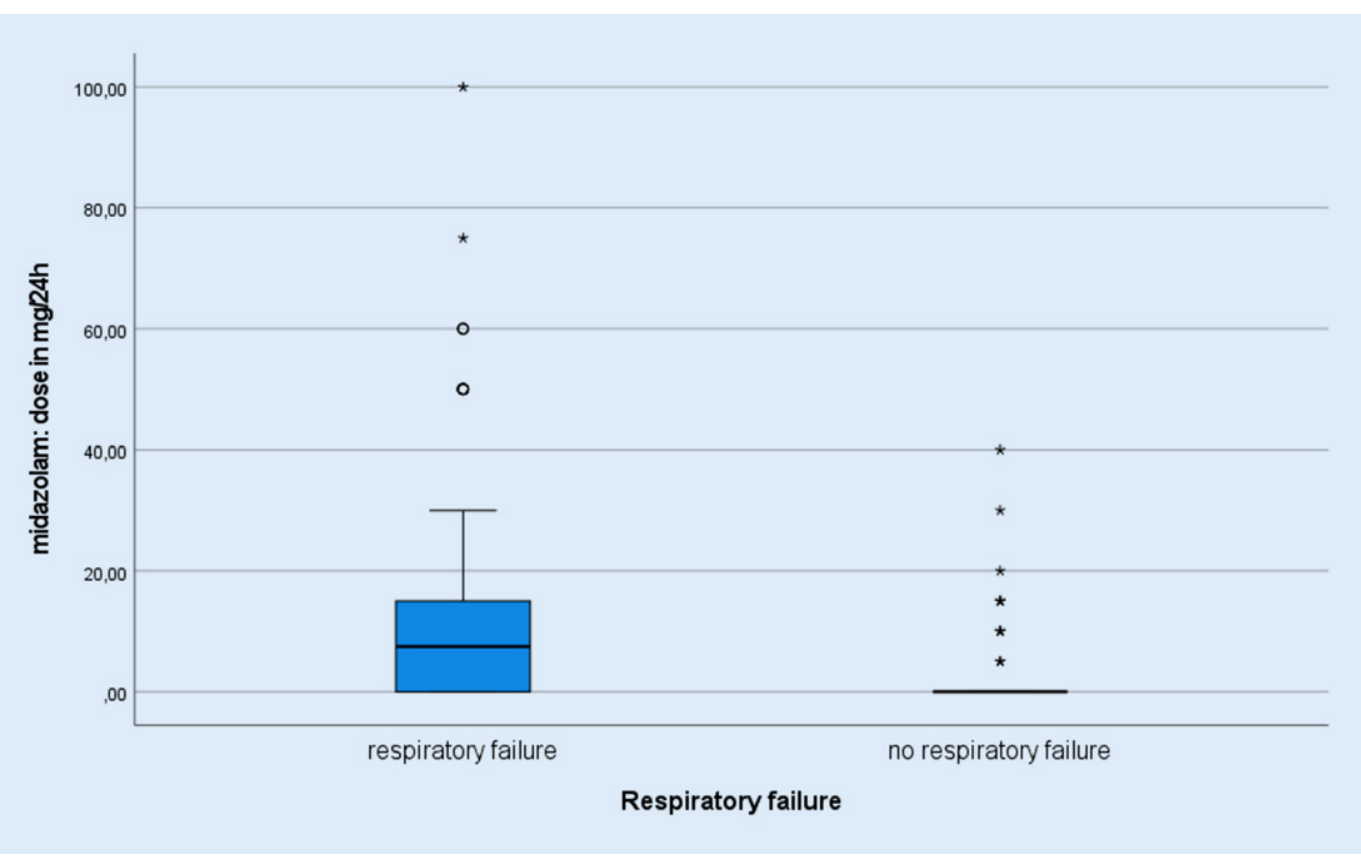

Fig. $3<$ Dosages of benzodiazepines in patients without respiratory failure were very low, a few cases $\left(^{*}\right)$ excepted. Circle outside the $95 \%$ confidence interval, asterisk highest dosages weak opioids was $66 \%$ and $37 \%$ respectively on the day of death [11]: however, the percentage of patients receiving opioids at the end of life varies strongly (14-83\% in USA) [1]. In a Belgian study on patients (non-COVID-19), 75 years and older dying in the hospital we noted a frequency of administration of opioids in $75.5 \%$ over the last $72 \mathrm{~h}$ before death, with a mean dosage of $27.7 \mathrm{mg} / 72 \mathrm{~h}$ [6].

When making comparisons with people dying from severe respiratory diseases, similar or even higher dosages, compared to our study, were observed. In two Dutch studies on nursing home residents with dementia and pneumonia $95 \%$ and $77 \%$ (mean dosage of $45 \mathrm{mg}$ SC morphine) received opioids, and $22.5 \%$ and $21 \%$ (mean dosage midazolam of $30 \mathrm{mg} / 24 \mathrm{~h}$ ) were pharmacologically sedated, respectively $[3,14]$.

Furthermore, it is known that important differences in usage of opioids in the endof-life stage in the oldest old exist, as described in PACE, a study in nursing homes residents (non-COVID-19) in 6 European countries, where the estimated prevalence of opioid prescription in the last 3 days of life varied from $18.5 \%$ in Poland to $77.9 \%$ in the Netherlands [13]. In sum, when comparing frequency of administration of opioids and dosages with non-COVID-19 situations, figures are comparable; however, doses of opioids and midazolam in our study were higher compared to doses used in patients dying with COVID-19 on palliative care units in other studies.

A possible explanation could be that on an acute ward a double track is followed in which both care goals of life prolongation and symptom control are upfront; this also explains the high concentration of supplemental oxygen that was administered, which we would not expect in a merely palliative care setting. High doses of morphine and midazolam were given starting from the point of view of comfort care in non-COVID-19 respiratory care, while, due to the double track followed, more uncertainty in patients and families existed resulting in more persisting symptoms and the need for higher dosage of oxygen and medication. Decisions not to escalate treatment in cases of respiratory failure was observed in two thirds of this cohort [10]. This prevalence is higher compared to non-COVID situations, possibly due to the fact that COVID-patients have a higher risk for ICU referral, with a longer stay and duration of mechanical ventilation and a higher risk for less successful rehabilitation. The degree of decisions not to escalate treatment was associated with the degree of premorbid frailty [10]. Furthermore, patients with the highest CFS (8-9) and therefore the poorest prognosis, are often not hospitalized but are taken care of at home or in residential care. This leads to the fact that hospitalized patients are often those with severe pathology but better chances of recovery, which could partially explain the higher dosages of opioids and benzodiazepines in our study.

The fact that the majority of patients in this cohort did not die (495 patients out of 711 survived) may justify the double track in acute wards [9]. More than 50\% of patients with a decision not to escalate treatment and were thus treated conservatively on the acute geriatric unit, survived on the acute geriatric ward. This reflects the fact that geriatricians are well placed to take care of the oldest old with COVID19 , partially because they are experts in assessing frailty, a major risk factor for inhospital mortality in the oldest old with COVID-19; however, one must stay precautious about the negative consequence of a longer dying process, causing a higher need for comfort medication. This hypothesis needs further exploration in prospective quantitative studies or studies with qualitative design.

Unfortunately, we have no data on comfort (dyspnea, agitation) of the patients in our study or the effect of the administered drugs. Given numbers are a description of what has been administered. Future studies should include dying symptom ratings and also the intention of the treatment.

Taking into account that, in Belgium, patients are seldomly admitted to a pallia- 
tive care unit directly from home or from residential care but are mostly hospitalized on an acute ward, and the fact that patients with the highest CFS (8-9) and therefore the poorest prognosis, are often not hospitalized but taken care of at home or in the residential care, our findings could help providing adequate palliative care to older patients dying from/with COVID-19 on regular wards. While the pandemic lasts patients and certainly the oldest old, will continue to have a high mortality from COVID-19 and will need a palliative care approach, in hospital, in residential care and at home and the majority of these patients will not be admitted to specialized palliative care units. With this descriptive study, we hope to contribute to further research on adequate doses of opioids and benzodiazepines and thus a better pharmacological treatment in an older population dying from/with COVID-19.

\section{Conclusion}

A high proportion of patients 80 years and older dying with COVID-19 (coronavirus disease 2019) in the hospital, were treated with oxygen, opioids and benzodiazepines in the last $24 \mathrm{~h}$ before death. With this descriptive study, we hope to contribute to the discussion and further research on the optimization of symptom control in an older population dying from/with COVID19.

\section{Corresponding address}

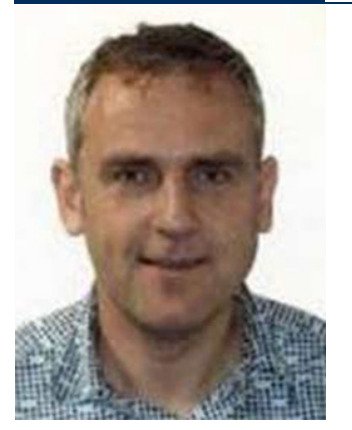

Wim H. Janssens, M.D.

Department of Geriatrics, University Hospital Ghent

Ghent, Belgium

wim.janssens@ugent.be
Terminalpflege bei ältesten Alten, die im Akutkrankenhaus an Covid-19 sterben. Eine multizentrische Studie über die pharmakologische Behandlung in den letzten $24 \mathrm{~h}$

Hintergrund: COVID-19 (Coronavirus disease 2019) hat eine hohe Sterblichkeit, insbesondere bei den Ältesten. Das Sterben an COVID-19 ist oft durch Symptome wie Atemnot und Erregung gekennzeichnet, aber die Datenlage zur medizinischen Behandlung in der Sterbephase ist begrenzt.

Ziel: In dieser Studie beschreiben wir die Gabe von Sauerstoff, Opioiden und Benzodiazepinen in den letzten $24 \mathrm{~h}$ vor dem Tod bei Patienten ab 80 Jahren, die mit COVID-19 auf Akutstationen versterben.

Material und Methoden: In dieser multizentrischen retrospektiven Studie wurden Patienten ab 80 Jahren, die im März und April 2020 ins Akutkrankenhaus eingeliefert wurden, aus 10 belgischen Akutkrankenhäusern rekrutiert. Sie alle wurden mit COVID-19 diagnostiziert und starben auf Nicht-Intensivstationen an COVID-19. Die Verabreichung von Sauerstoff, Opioiden und Benzodiazepinen wurde in den letzten $24 \mathrm{~h}$ vor dem Tod registriert.

Ergebnisse: Von den Patienten erhielten $85 \%$ Sauerstoff, die Hälfte sogar über eine Maske, die mindestens 10 I Sauerstoff pro Minute lieferte. Ein Großteil (84,3\%) der Patienten wurde mit Opioiden (Morphin) behandelt. Die mittlere Dosis des SC-MorphinÄquivalents betrug 31,3 mg/24h (Bereich: 2-120 mg; SD 21,6). Mehr als die Hälfte der Patienten (52,8\%) erhielt Benzodiazepine, meist Midazolam. Die mittlere Dosis von Midazolam betrug 20,4 mg/24h (Bereich: 1-100 mg; SD 15,4). Die Dosierungen von Morphin und Midazolam unterschieden sich nicht in Abhängigkeit von Gebrechlichkeit oder Komorbiditäten. Ältere COVID-19-Patienten, die an Atemversagen starben, hatten eine höhere Midazolam-Dosierung $(p=0,002)$, aber keine Morphin-Dosierung $(p=0,11)$.

Diskussion: Ein hoher Anteil der Patienten ab 80 Jahren, die im Krankenhaus an COVID-19 starben, wurde in den letzten $24 \mathrm{~h}$ vor dem Tod mit Sauerstoff, Opioiden und Benzodiazepinen behandelt. Wir hoffen, mit dieser deskriptiven Studie einen Beitrag zur Diskussion und weiteren Forschung zur Optimierung der Symptomkontrolle bei einer älteren Bevölkerung, die an/mit COVID-19 stirbt, zu leisten.

\section{Schlüsselwörter}

SARS-CoV-2 $\cdot 80$ Jahre und älter $\cdot$ Lebensende $\cdot$ Pharmakologische Behandlung · Opioid

\section{Declarations}

Conflict of interest. W. H. Janssens, N.J. Van Den Noortgate and R.D. Piers declare that they have no competing interests.

The study was approved by the central ethics committee (Ghent University Hospital, Belgian Registration number BC-07858) and all local ethics committees. Informed consent was waived because of the retrospective and non-interventional nature of the study and because strict anonymity during data processing was guaranteed.

\section{References}

1. Bailey FA, Williams BR, Goode PS et al (2012) Opioid pain medication orders and administration in the last days of life. JPain Symptom Manag 44:681-691

2. Belgium COVID-19Dashboard-Sciensano-Deaths; https://www.sciensano.be/en/covid-19-data

3. Hendriks S, Smalbrugge M, Hertogh $C$, van der Steen J (2014) Dying with dementia: symptoms, treatment, and quality of life in the last week of life.
J Pain Symptom Manag 47(4):710-720. https:// doi.org/10.1016/j.jpainsymman.2013.05.015

4. Hetherington $L$, Johnston $B$, Kotronoulas $G$ et al (2020) COVID-19 and hospital palliative care-A service evaluation exploring the symptoms and outcomes of 186 patients and the impact on specialist hospital palliative care. Palliat Med 34(9):1256-1262. https://doi.org/10.1177/ 0269216320949786

5. Jackson T, Hobson K, Clare H et al (2020) End-oflife care in COVID-19: an audit of pharmacological management in hospital inpatients. Palliat Med 34(9):1235-1240. https://doi.org/10.1177/ 0269216320935361

6. Janssens WH, Van Den Noortgate NJ, Piers RD (2021) Pharmacological treatment in the dying geriatric patient: describing use and dosage of opioids in the acute geriatric wards and palliative care units of 3 hospitals. Eur Geriatr Med 12(3):545-550. https://doi.org/10.1007/s41999021-00496-2

7. Lovell N, Maddocks M, Etkind SN et al (2020) Characteristics, symptom management, and outcomes of 101 patients with COVID-19 referred for hospital palliative care. J Pain Symptom 


\section{Original Contributions}

Manag 60(1):e77-e81. https://doi.org/10.1016/j. jpainsymman.2020.04.015

8. Onder G, Rezza G, Brusaferro S (2020) Case-fatality rate and characteristics of patients dying in relation to COVID-19 in Italy. JAMA 323(18):1775-1776. https://doi.org/10.1001/jama.20204683 (Erratum in: JAMA. 2020 Apr 28;323(16):1619)

9. Piers R, Janssens W, Cobbaert Ketal (2021) Letter to the editor: Premorbid frailty is a better prognostic indicator than age in oldest-old hospitalized with COVID-19. J Am Med Dir Assoc 22(3):514-516 https://doi.org/10.1016/j.jamda.2021.01.059

10. Piers R, Van Braeckel E, Benoit D, Van Den Noortgate N (2021) Early resuscitation orders in hospitalized oldest-old with COVID-19: a multicenter cohort study. Palliat Med 35(7):1288-1294. https://doi.org/10.1177/02692163211018342

11. Sandvik RK, Selbaek G, Bergh S, Aarsland D, Husebo BS (2016) Signs of imminent dying and change in symptom intensity during pharmacological treatment in dying nursing home patients: a prospective trajectory study. J Am Med Dir Assoc 17(9):821-827. https://doi.org/10.1016/j.jamda. 2016.05.006

12. Strang P, Bergström J, Lundström S (2020) Symptom relief is possible in elderly dying COVID19 patients: a national register study. J Palliat Med. https://doi.org/10.1089/jpm.2020.0249

13. Tanghe M, Van Den Noortgate N, Pivodic L et al (2019) Opioid, antipsychotic and hypnotic use in end of life in long term care facilities in 6 European countries: results of PACE. Eur J Public Health 29(1):74-79. https://doi.org/10.1093/eurpub/ cky196

14. van der Maaden $T$, van der Steen J, de Vet $H$, Hertogh C, Koopmans R (2016) Prospective observations of discomfort, pain, and dyspnea in nursing home residents with dementia and pneumonia. J Am Med Dir Assoc 17(2):128-135. https://doi.org/10.1016/j.jamda.2015.08.010

15. Wiersinga WJ, Rhodes A, Cheng AC, Peacock SJ, Prescott HC (2020) Pathophysiology, transmission, diagnosis, and treatment of coronavirus disease 2019 (COVID-19): a review. JAMA 324(8):782-793. https://doi.org/10.1001/jama.2020.12839

16. Wu Z, Tang Y, Cheng Q (2021) Diabetes increases the mortality of patients with COVID-19: a metaanalysis. Acta Diabetol 58(2):139-144. https://doi. org/10.1007/s00592-020-01546-0

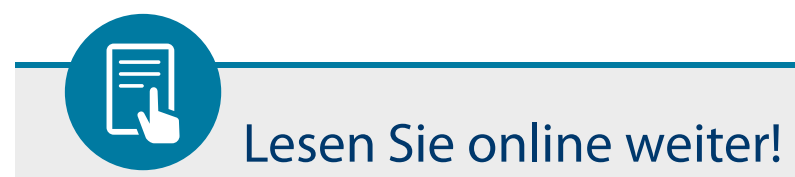

Als Abonnent der Zeitschrift für Gerontologie und Geriatrie können Sie die Zeitschrift auch online lesen:

www.springermedizin.de/zgg

So einfach erhalten Sie Zugang zur Online-Plattform:

- Registrieren Sie sich einmalig auf www.springermedizin.de/register

- Ihr Benutzername entspricht Ihrer E-Mail-Adresse, Ihr Passwort können Sie frei wählen und später jederzeit unter "Mein Profil“ ändern.

- Geben Sie bei der Registierung die Lieferadresse Ihrer Zeitschrift an. Damit wird Ihr AboZugang auf springermedizin.de freigeschaltet.

Sind Sie bereits bei SpringerMedizin.de registriert?

Dann wird Ihr Zeitschriftenabonnement automatisch Ihrem Online-Nutzerkonto hinzugefügt.

Sollten die Angaben Ihres Online-Accounts nicht eindeutig mit den Angaben Ihres Zeitschriften-Abonnements übereinstimmen, kann die Zuordnung nicht sicher erfolgen. In diesem Fall und bei allen anderen Fragen zum Online-Zugang kontaktieren Sie bitte unseren Kundenservice unter: kundenservice@springermedizin.de

Telefonisch erreichen Sie den Kundenservice montags bis freitags von 9.00 bis 17.00 Uhr kostenfrei unter 0800-77 80777. 